\title{
Experimental Research on Effect of Heat Source on Performance of Transcritical $\mathrm{CO}_{2}$ System
}

\author{
Yingfu Liu1, a, Tongzhen Jia1, b, Guangya $\mathrm{Jin}^{2, \mathrm{c}}$ \\ ${ }^{1}$ Baoding Electric Power VOC. \& TECH. College, 1278 North Lekai Street, \\ Baoding 071051, Hebei, China \\ ${ }^{2}$ North China Electric Power University, 619 North Yonghua Street, \\ Baoding 071003, Hebei, China \\ aliuyingfu2008@163.com, b135290966@qq.com, crongyz@163.com
}

Keywords: Transcritical $\mathrm{CO}_{2}$ system, Coefficient of performance, Heat source, Experimental research.

Abstract. In this paper, the transcritical $\mathrm{CO}_{2}$ system is experimental studied, influence of heat source on system performance is analyzed. The experimental results show that the cooling water flow has no obvious effect on the system performance and it may be owed to the limitations of this experimental device. The cooling water temperature has a great impact on the system performance, $\mathrm{COP}_{h}$ decreases about $21.7 \%, \mathrm{COP}_{c}$ decreases about $26.6 \%$ from the maximum value when the cooling water temperature range from $25^{\circ} \mathrm{C}$ to $35^{\circ} \mathrm{C}$. The chilled water flow and temperature has a little impact on heating coefficient of performance, while it has a great impact on the cooling coefficient of performance. When $\mathrm{COP}_{h}$ and $\mathrm{COP}_{c}$ get the extreme value with the increase of chilled water flow, $\mathrm{COP}_{h}$ decreases about $2.61 \%, \mathrm{COP}_{c}$ increases about $29 \%$. $\mathrm{COP}_{h}$ increases about $7.5 \%, \mathrm{COP}_{c}$ increases about $55.1 \%$ when the chilled water temperature ranges from $7^{\circ} \mathrm{C}$ to $17^{\circ} \mathrm{C}$.

\section{Introduction}

Natural refrigerants are increasingly becoming the refrigerant of choice to replace the environmentally harmful CFCs and HCFCs, and the application of natural refrigerant $\mathrm{CO}_{2}$ is of great significance to reduce the greenhouse effect and ozone depletion. The former IIR chairman G. Lorentzen [1] is the first to advance the $\mathrm{CO}_{2}$ transcritical cycle, and think that $\mathrm{CO}_{2}$ is "the most prospects refrigerant of the 21 st century". $\mathrm{CO}_{2}$ has its unique advantages [2] as a refrigerant such as environmental safety, favorable thermodynamic properties, and non-flammability.

In recent years, several researchers [3-6] have investigated the transcritical $\mathrm{CO}_{2}$ system. But the coefficient of performance of the transcritical system is not high because of their lower critical temperature $\left(31^{\circ} \mathrm{C}\right)$. Therefore, the key to promote the transcritical $\mathrm{CO}_{2}$ cycle is to improve the system performance. It is required to investigate the performance improvement of the transcritical $\mathrm{CO}_{2}$ system. In the paper, the transcritical $\mathrm{CO}_{2}$ system is experimental investigated, and influence of cooling water and chilled water on the heat output $\left(Q_{h}\right)$, refrigerating capacity $\left(Q_{\mathrm{c}}\right)$, compressor work $(W)$, heating coefficient of performance $\left(\mathrm{COP}_{h}\right)$ and cooling coefficient of performance $\left(C O P_{c}\right)$ is analyzed, which could provide a basis for the optimization of transcritical $\mathrm{CO}_{2}$ refrigeration cycle. 


\section{Experimental Apparatus}

Fig. 1 shows a schematic diagram of the experimental apparatus, which consists of three loops: transcritical $\mathrm{CO}_{2}$ refrigeration system, cooling water system and chilled water system. The transcritical $\mathrm{CO}_{2}$ refrigeration system as the core part of the system consists of a compressor, a gas cooler, a pre-evaporator, an evaporator, a throttle valve, an internal heat exchanger, a gas-liquid separator and an oil separator. A manual throttle valve is used. The piston-type compressor has theoretical displacement of $3.5 \mathrm{~m}^{3} / \mathrm{h}$.

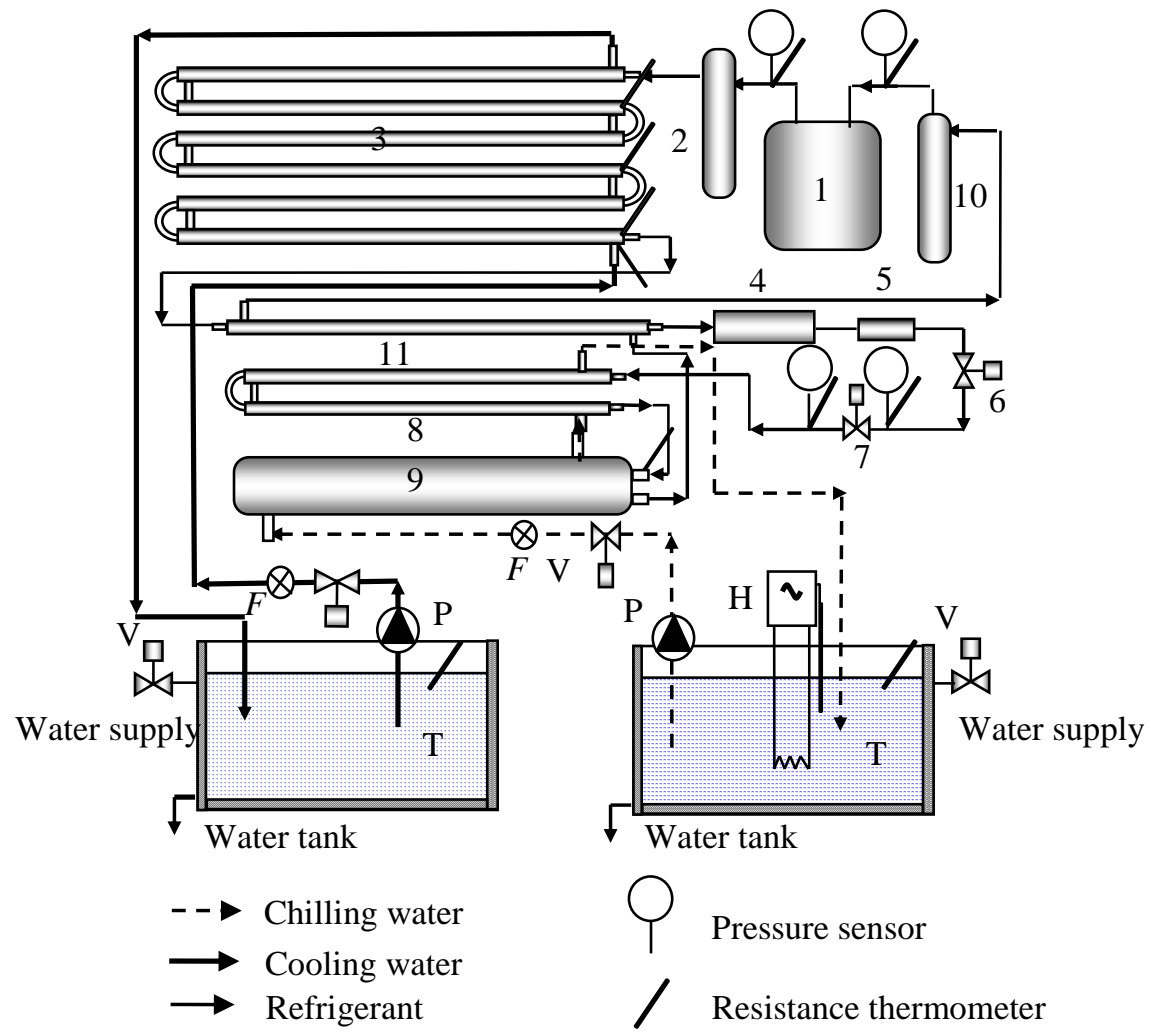

Fig. 1 Schematic diagram of the experimental apparatus

1-Compressor 2-Oil separator 3-Gas cooler 4-Reservoir 5-Drier-filter 6-Magnet valve 7-Throttle valve

8-Pre-evaporator 9- Evaporator 10-Gas-liquid separator 11-Internal heat exchanger

F-Rotermeter V-Control valve P-Water pump H-Heater T-Water tank

The data collection including the pressure, temperature of refrigerant, chilled water and cooling water temperature, power and current of compressor and the heater. The temperature was measured using WZP-BW-type platinum resistance thermometer, the calibration of measurement error is $\pm 0.1{ }^{\circ} \mathrm{C}$. Silicon-proliferation BP800-type pressure sensor with accuracy of $0.5 \%$ was used to measure the pressure. Rotameter was used to measure the flow of cooling water and chilled water, and its error is less than $3 \%$.

\section{Analysis of Experimental Results}

\section{Influence of Cooling Water on System Performance}

Fig.2 shows the variation of heat output $\left(Q_{h}\right)$, refrigerating capacity $\left(Q_{\mathrm{c}}\right)$, compressor work $(W)$, heating coefficient of performance $\left(C O P_{h}\right)$ and cooling coefficient of performance $\left(C O P_{c}\right)$ with cooling water flow $\left(W_{1}\right)$. It shows that heat output, refrigerating capacity and compressor work changed slightly with the increase of cooling water flow, which cause the heating coefficient of 
performance and cooling coefficient of performance changed a little. The cooling water flow has no obvious effect on the system performance may be owed to the limitations of this experimental device.

Fig.3 shows the variation of heat output $\left(Q_{h}\right)$, refrigerating capacity $\left(Q_{\mathrm{c}}\right)$, compressor work $(W)$, heating coefficient of performance $\left(C O P_{h}\right)$ and cooling coefficient of performance $\left(C O P_{c}\right)$ with cooling water temperature $\left(T_{1}\right)$. It shows that heat output decreases slowly with the increase of cooling water temperature, while refrigerating capacity first increases slowly and then decreases with the increase of cooling water temperature, and the compressor work has a linear increase with the increase of cooling water temperature. System performance corresponding to changes of heat output, refrigerating capacity and compressor work, heating coefficient of performance showing the trend of decreases, and cooling coefficient of performance showing the trend of first increases and then decreases. When the cooling water temperature range from $25^{\circ} \mathrm{C}$ to $35^{\circ} \mathrm{C}, \mathrm{COP}_{h}$ decreases about $21.7 \%, \mathrm{COP}_{c}$ decreases about $26.6 \%$ from the maximum value. The cooling water temperature has a great impact on the system performance.

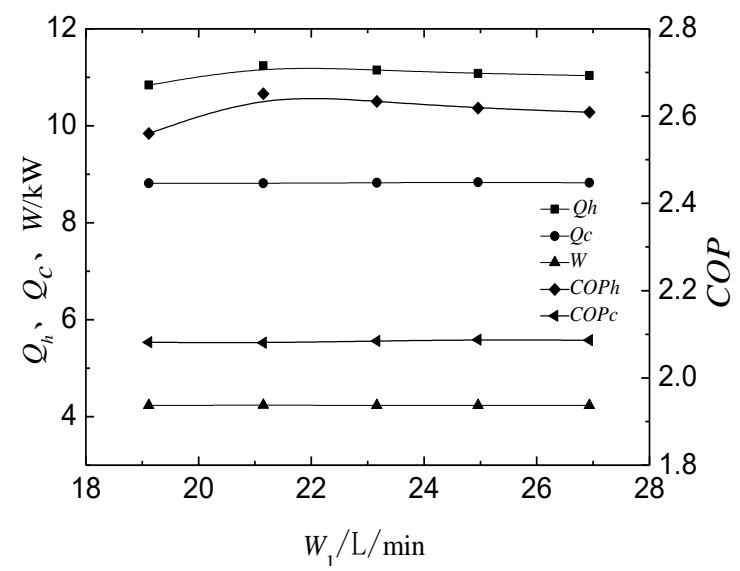

Fig.2. Variation of $Q_{h}, Q_{\mathrm{c}}, W, C O P_{h}$ and $\mathrm{COP}_{c}$ with cooling water flow

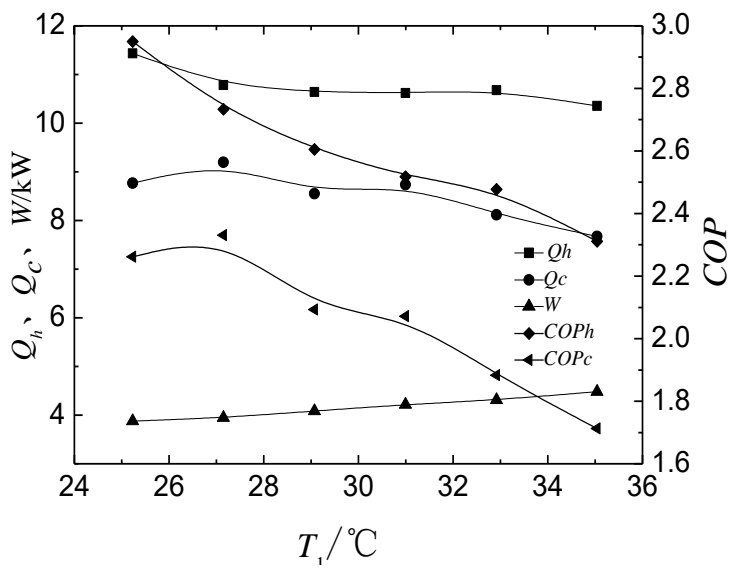

Fig.3. Variation of $Q_{h}, Q_{\mathrm{c}}, W, C O P_{h}$ and $C O P_{c}$ with cooling water temperature

\section{Influence of Chilled Water on System Performance}

Fig.4 shows the variation of heat output $\left(Q_{h}\right)$, refrigerating capacity $\left(Q_{c}\right)$, compressor work $(W)$, heating coefficient of performance $\left(C O P_{h}\right)$ and cooling coefficient of performance $\left(C O P_{c}\right)$ with chilled water flow $\left(W_{2}\right)$. It shows that heat output first decreases slowly and then increases, while refrigerating capacity first increases fast and then decreases slowly with the increase of chilled water flow, and the compressor work changed slightly. Heating coefficient of performance first decreases and then increases with the increase of chilled water flow, but cooling coefficient of performance first increases fast and then decreases slowly. The chilled water flow has a little impact on heating coefficient of performance, while it has a great impact on the cooling coefficient of performance. When they get the extreme value with the increase of chilled water flow, $\mathrm{COP}_{h}$ decreases about $2.61 \%, C O P_{c}$ increases about $29 \%$.

Fig.5 shows the variation of heat output $\left(Q_{h}\right)$, refrigerating capacity $\left(Q_{c}\right)$, compressor work $(W)$, heating coefficient of performance $\left(C O P_{h}\right)$ and cooling coefficient of performance $\left(C O P_{c}\right)$ with chilled water temperature $\left(T_{2}\right)$. It shows that heat output first increases slowly and then almost does not change, while refrigerating capacity has a obviously increase with the increase of chilled water temperature, and the compressor work has a little increase. System performance corresponding to changes of heat output, refrigerating capacity and compressor work, heating coefficient of 
performance showing the trend of first increases slowly and then decreases slowly, and cooling coefficient of performance showing the trend of increases fast. When the chilled water temperature ranges from $7{ }^{\circ} \mathrm{C}$ to $17^{\circ} \mathrm{C}, \mathrm{COP}_{h}$ increases about $7.5 \%, C O P_{c}$ increases about $55.1 \%$. The chilled water temperature has a great impact on the cooling coefficient of performance.

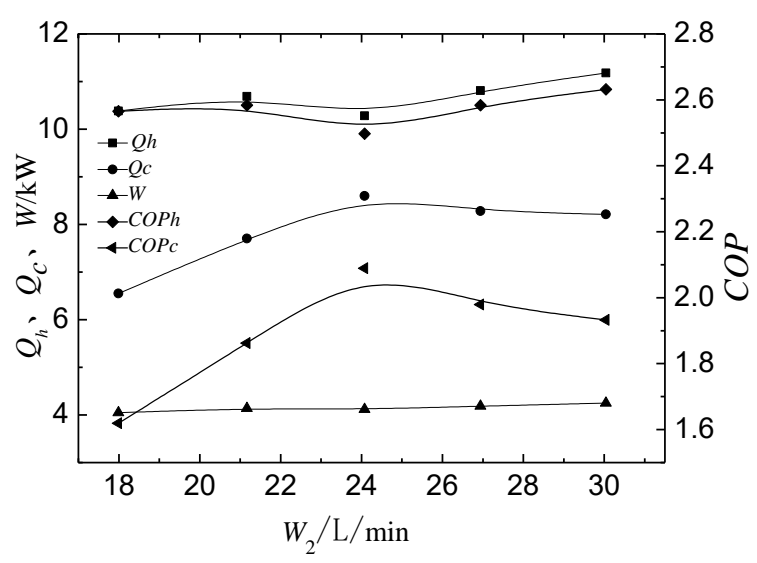

Fig.4. Variation of $Q_{h}, Q_{\mathrm{c}}, W, C O P_{h}$ and $\mathrm{COP}_{c}$ with chilled water flow

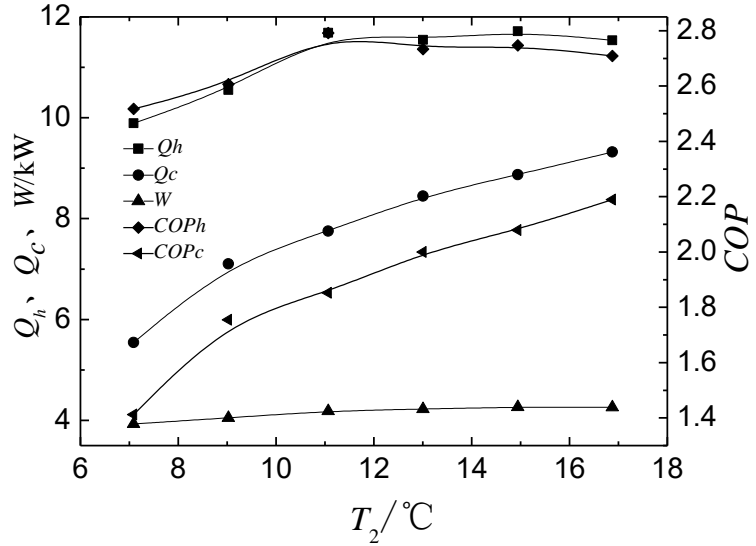

Fig.5. Variation of $Q_{h}, Q_{\mathrm{c}}, W, C O P_{h}$ and $C O P_{c}$ with chilled water temperature

\section{Conclusions}

In this paper, the transcritical $\mathrm{CO}_{2}$ system is experimental studied, influence of heat source on system performance is analyzed. The experimental results show that the cooling water flow has no obvious effect on the system performance which may be owed to the limitations of this experimental device. The cooling water temperature has a great impact on the system performance, $\mathrm{COP}_{h}$ decreases about $21.7 \%, \mathrm{COP}_{c}$ decreases about $26.6 \%$ from the maximum value when the cooling water temperature range from $25^{\circ} \mathrm{C}$ to $35^{\circ} \mathrm{C}$. The chilled water flow and temperature has a little impact on heating coefficient of performance, while it has a great impact on the cooling coefficient of performance. When $\mathrm{COP}_{c}$ gets the maxmium value with increase of chilled water flow it increases about $29 \%$, and when the chilled water temperature ranges from $7^{\circ} \mathrm{C}$ to $17^{\circ} \mathrm{C}$, $C O P_{c}$ increases about $55.1 \%$.

\section{References}

[1] G. Lorentzen. Revival of carbon dioxide as a refrigerant. International Journal of Refrigeration, 1994, 17(5):292-301.

[2] Andy Pearson. Carbon dioxide-new uses for an old refrigerant. International Journal of Refrigeration, 2005, 28, 1140-1148.

[3] E.A. Groll, J.H. Kim. Review of recent advances toward transcritical $\mathrm{CO}_{2}$ cycle technology. HVAC \& R Research, 2007, 13 (3): 499-520.

[4] Ramon Cabelloa, Daniel Sancheza, Jorge Patinoa, Rodrigo Llopisa, Enrique Torrellab. Experimental analysis of energy performance of modified single-stage $\mathrm{CO}_{2}$ transcritical vapour compression cycles based on vapour injection in the suction line. Applied Thermal Engineering, Vol. 47, 86-94, 2012.

[5] Eunsung Shina, Chasik Parkb, Honghyun Choc. Theoretical analysis of performance of a two-stage compression $\mathrm{CO}_{2}$ cycle with two different evaporating temperatures. International Journal of Refrigeration, Vol. 47, 164-175, 2014.

[6] Jahar Sarkar. Review on Cycle Modifications of Transcritical $\mathrm{CO}_{2}$ Refrigeration and Heat Pump Systems. Journal of Advanced Research in Mechanical Engineering, 2010, 1(1): 22-29. 